\title{
Episcleral Venous Pressure and Glaucoma
}

\author{
Marlene Moster, Parul Ichhpujani \\ Wills Eye Institute, Jefferson Medical College, Philadelphia, PA, USA
}

\section{BACKGROUND}

The pioneering work of Lauber ${ }^{1}$ in the early 20th century was the first stepping stone towards understanding the role of episcleral venous pressure in aqueous humor dynamics. This led to Seidel's ${ }^{2}$ observation in 1923 that India ink injected in the anterior chamber gained access to episcleral veins, and in 1942 Ascher ${ }^{3}$ made the first direct observation of the aqueous veins.

\section{EPISCLERAL VENOUS PRESSURE AND AQUEOUS OUTFLOW}

Aqueous outflow via the conventional outflow pathway is dependent on the pressure gradient between intraocular pressure (IOP) and episcleral venous pressure (EVP). According to the Goldmann equation: IOP = F/C + EVP (F aqueous humor inflow, C outflow facility). This implies that EVP elevation uncompensated by reduced aqueous inflow or increased aqueous outflow facility will result in increased IOP. ${ }^{4}$ The definite relation between EVP and IOP, however, is unclear. The normal episcleral venous pressure is 8-10 $\mathrm{mm}$ Hg; variability depends on the measurement technique. ${ }^{5}$ It is thought that for every $\mathrm{mm} \mathrm{Hg}$ rise in EVP, there is an equal increase in the intraocular pressure; although it has been suggested that the magnitude of rise of intraocular pressure can be more. ${ }^{6}$

\section{EFFECT OF ANGIOARCHITECTURE ON EVP}

The episcleral vasculature shows morphological specialities that distinguish it from other vessels. There are only few capillaries, but numerous arteriovenous anastomoses and an extended network of venules with a wall containing circularly arranged muscle cells. Furthermore there is a strikingly dense vasoconstrictive and vasodilative innervation of the veins. ${ }^{7}$ Animal studies show that the elaborated innervation of the episcleral anastomoses is a prerequisite for a subtle modulation of the blood flow and possibly of the aqueous humor outflow dynamics. ${ }^{8}$ However, the role of the episcleral vasculature and its specialities for regulation of IOP as well as possible therapeutic aspects are still not fully understood and require further investigation.

\section{EFFECT OF POSTURE ON EVP AND IOP}

EVP has been shown to be influenced by body posture. In a study, mouse EVP was successfully measured based on the detection of erythrocyte reflux from an episcleral vein into Schlemm's canal. Both EVP and IOP increased with the degree of the head-down body position. ${ }^{9}$ Episcleral venous pressure remains relatively constant throughout the day. It increases in the supine position with a corresponding increase in IOP. ${ }^{10}$ Another study has shown no difference in the intraocular pressure and episcleral venous pressure in the younger and older group in the sitting position, but they were higher in the supine position for older subjects. ${ }^{11}$

\section{EVP IN NORMAL AND GLAUCOMATOUS EYES}

EVP in normal eyes and in eyes with open angle glaucoma have not be shown to be significantly different. ${ }^{12-14}$ Kupfer reported that ocular hypertensive eyes have a slightly lower EVP than normal eyes, but his group was small for a statistical comparison. ${ }^{15}$ Talusan also found that EVP of the patients with ocular hypertension were found to be significantly lower than those of the patients with glaucoma and the normal patients. ${ }^{16}$ Other investigators noted that the EVP/intraocular pressure (IOP) ratio was significantly different in NTG patients $(80.0 \%$ $+/-3.2)$ in comparison with both POAG patients $(67.1 \%+/-2.8)$ and controls $(69.2 \%+/-2.4)$. Regression analysis revealed a significant linear correlation between EVP and IOP in both the NTG and the POAG group. In the control group, however, the correlation was weak. ${ }^{17}$

\section{CAUSES OF ELEVATED EVP}

Causes of elevated EVP may be divided into three different groups: venous obstruction, which includes thyroid ophthalmopathy, retrobulbar tumor, cavernous sinus or orbital vein thrombosis, episcleral or orbital vein vasculitis, and 
obstruction of the superior vena cava; arteriovenous anomalies, including carotid artery-cavernous sinus fistula, orbital varices, dural shunts and Sturg-Weber syndrome; and idiopathic. ${ }^{18,19}$ Ocular laterality, motility dysfunction and fundoscopic signs of venous congestion are dependent upon the level of blockage.

\section{CLINICAL PRESENTATION}

\section{Idiopathic Elevated Episcleral Venous Pressure (IEEVP)}

The idiopathic type of elevation of EVP is a diagnosis of exclusion after intraorbital and intracranial pathology has been excluded. ${ }^{20}$ The diagnosis is based on the clinical findings of prominent (arterialized) episcleral veins (Fig. 1), elevated IOP causing characteristic optic nerve and/or visual field changes typical of glaucoma and an open angle on gonioscopy. Diagnostic evaluation should include a complete ophthalmic examination, radiological imaging ${ }^{21}$ such as an MRI and noninvasive vascular imaging to exclude a cerebrovascular disorder. Idiopathic episcleral venous stasis with secondary open angle glaucoma (Radius Maumenee syndrome) responds to microsurgical sinusotomy to reduce the pressure gradient from Schlemmn's canal to episcleral vessels. ${ }^{22,23}$

\section{Venous Obstruction}

Elevated EVP may be present in severe cases of thyroid ophthalmopathy with marked proptosis and orbital congestion (Fig. 2). ${ }^{24}$ Lesions of upper thorax may obstruct venous return from the head and produce exophthalmos, edema and cyanosis of the face. ${ }^{25}$

\section{Arteriovenous Fistulas}

Carotidocavernous sinus fistulas can be either spontaneous or traumatic. The mixing of arterial and venous pressure leads to a reduction in arterial pressure and an elevation in EVP. The pattern of venous drainage, either anterior into the ophthalmic veins or posterior into the petrosal sinuses, often dictates the clinical findings and radiographic appearance. Anterior drainage typically leads to the most dramatic ocular findings and enlargement of the superior orbital vein, the latter often detectable with CT or MRI. These patients have prominent episcleral and conjunctival vessels alongwith elevated IOP and closure of the fistula is the primary condition required for favorable IOP control. ${ }^{26,27}$ Arteriovenous anomalies may be treated primarily with intravascular embolization and balloon occlusion. Newer techniques using transvenous approaches have also shown promising outcome. ${ }^{28}$

\section{Orbital Varices}

Orbital varices typically have intermittent episodes of raised EVP associated with valsalva maneuver. Since EVP is normal between episodes, glaucoma is not common. ${ }^{29}$

\section{Sturge-Weber Syndrome}

IOP elevation may occur due to the episcleral hemangiomas with arteriovenous fistulas. ${ }^{30}$ Phelps proposed that the veins draining aqueous from the canal of Schlemm are a part of an intrascleral or episcleral hemangioma or the canal of Schlemmn itself may be part of the hemangioma. Arteriovenous shunts in the hemangioma raise episcleral venous pressure, which in turn elevates intraocular pressure. ${ }^{31}$ Blood may be seen in Schlemmn's canal on gonioscopy but it is not pathognomonic (Fig. 3). In glaucoma associated with Sturge-Weber syndrome, medical treatment often fails to control intraocular pressure, thus requiring surgical intervention that may result in serious complications. ${ }^{32}$

Goniotomy, ${ }^{33}$ trabeculotomy, ${ }^{33}$ combined trabeculotomytrabeculectomy, ${ }^{34}$ drainage devices ${ }^{35-37}$ and nonpenetrating filtering surgery ${ }^{38}$ have been tried with variable results.

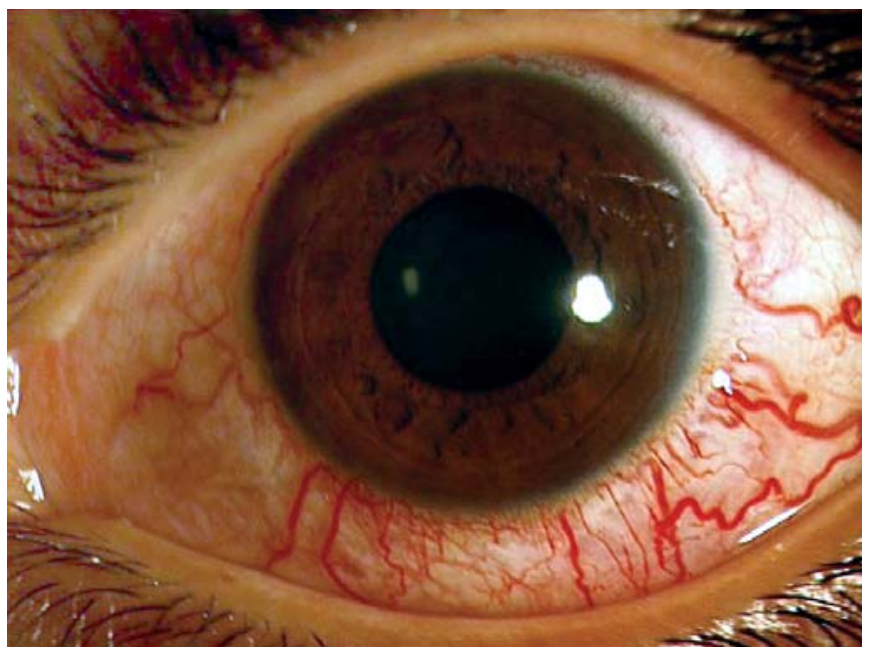

Fig. 1: Prominent episcleral vessels

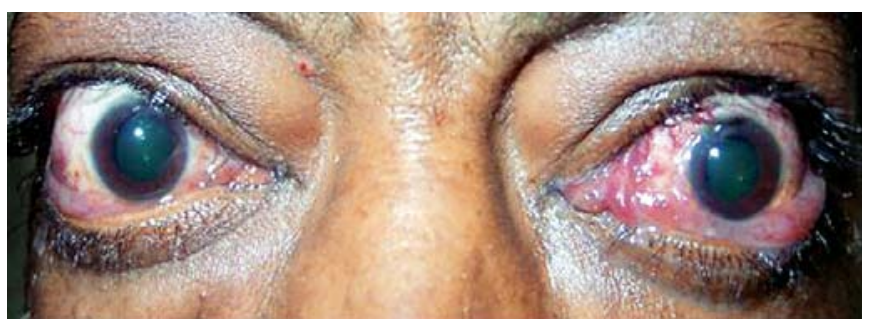

Fig. 2: Episcleral venous congestion secondary to thyroid associated ophthalmopathy 


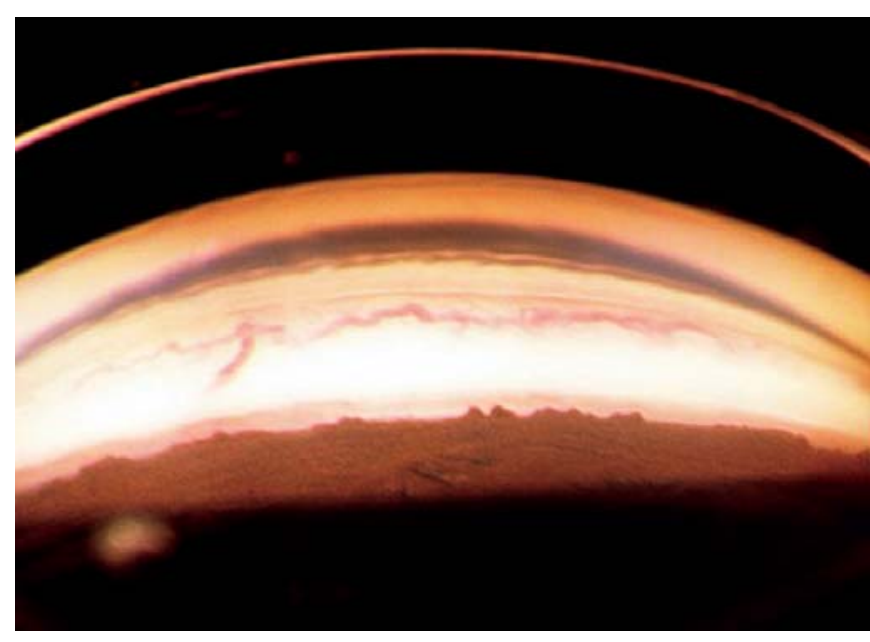

Fig. 3: Goniopicture showing blood in Schlemmn canal of a patient of Sturge-Weber syndrome

Choroidal effusion and postoperative serous retinal detachment are possible complications. ${ }^{39,40}$ Moderately tight scleral flap suture, posterior sclerostomy at the time of filtering surgery and delayed suture lysis may be required to prevent choroidal effusion. Drainage implants cannot be used in cases with severe proptosis and orbital congestion due to space limitations.

\section{Orbital Amyloidosis}

Rare cases of localized orbital amyloidosis with secondary glaucoma due to elevated EVP have been reported. ${ }^{41,42}$ Nelson et al postulate that perivascular infiltration of amyloid around extraocular vessels may cause elevated EVP. ${ }^{41}$

\section{Diagnosis and Management}

Theses include ultrasound biomicroscopy, ${ }^{43}$ orbital ultrasonography, computerized axial tomography, magnetic resonance imaging and angiography. ${ }^{44}$ The finding of a hyperintense signal in the cavernous sinus on MRA source imaging provides additional, and sometimes the only, neuroradiographic Carotico-cavernous fistula evidence. In addition a team approach involving a glaucomatologist, neuroophthalmologist, neuroradiologist and an orbital surgeon are often necessary for accurate diagnosis and appropriate management.

Treatment of underlying cause of elevated EVP is ideal, but may not be always possible. Miotics and laser trabeculoplasty are not very helpful due to normal facility of outflow in these patients. Aqueous suppressants may help in some patients. Surgical management holds the key for controlling elevated intraocular pressure, but sudden decompression should be avoided as these are prone to choroidal effusion. However, even if the underlying pathology is identified and treated, the IOP likely may remain elevated if the venous system has had sufficient time to arteriolize.

\section{REFERENCES}

1. Ascher KW. The aqueous veins: Physiological importance of the visible elimination of fluid. Am J Ophthalmol 1942;25:1147.

2. Seidel E. Weitere experimentelle Unturschunugen uber di quelle und den Verlauf der intraokularen Saftrosrommung XX. Uber die Messung des Blutruckes in dem episcleral Venegeflecht, den vordoren ciliarund den Wirbelenen normaler Augen.Graefes Arch klin Exp Ophthalmol112;252:1023.

3. Ascher KW. Aqueous veins. Am J Ophthalmol 1942;25:31.

4. Brubaker RF. Goldmann's equation and clinical measures of aqueous dynamics. Exp Eye Res 2004 Mar;78(3):633-37.

5. Brubaker RF. Determination of episcleral venous pressure in the eye. A comparison of three methods. Arch Ophthalmol 1967 Jan; 77(1):110-14.

6. Kollarits CR, Gaasterland D, Di Chiro G, Christiansen J, Yee RD. Management of a patient with orbital varices, visual loss, and ipsilateral glaucoma. Ophthalmic Surg 1977 Oct;8(5):54-62.

7. Selbach JM, Rohen JW, Steuhl KP, Lütjen-Drecoll E. Angioarchitecture and innervation of the primate anterior episclera.Curr Eye Res 2005 May;30(5):337-44.

8. Selbach JM, Schönfelder U, Funk RH. Arteriovenous anastomoses of the episcleral vasculature in the rabbit and rat eye. J Glaucoma 1998 Feb;7(1):50-57.

9. Aihara M, Lindsey JD, Weinreb RN. Episcleral venous pressure of mouse eye and effect of body position. Curr Eye Res 2003 Dec; 27(6):355-62.

10. Blondeau P, Tétrault JP, Papamarkakis C. Diurnal variation of episcleral venous pressure in healthy patients: a pilot study. J Glaucoma 2001 Feb;10(1):18-24.

11. Sultan M, Blondeau P. Episcleral venous pressure in younger and older subjects in the sitting and supine positions. J Glaucoma. 2003 Aug;12(4):370-73.

12. Linner E. Further studies of the episcleral venous pressure in glaucoma. Am J Ophthalmol 1956 Apr;41(4):646-51.

13. Podos SM, Minas TF, Macri FJ. A new instrument to measure episcleral venous pressure. Comparison of normal eyes and eyes with primary open-angle glaucoma. Arch Ophthalmol 1968 Aug; 80(2):209-13.

14. Leith AB. Episcleral venous pressure in tonography. $\mathrm{Br} \mathrm{J}$ Ophthalmol 1963;47:271-78.

15. Kupfer C. Clinical significance of pseudofacility. Am J Ophthalmol 1973;75:193-204.

16. Talusan ED, Schwartz B. Episcleral venous pressure. Differences between normal, ocular hypertensive, and primary open angle glaucomas. Arch Ophthalmol 1981 May;99(5):824-28.

17. Selbach JM, Posielek K, Steuhl KP, Kremmer S. Episcleral venous pressure in untreated primary open-angle and normal-tension glaucoma. Ophthalmologica 2005 Nov-Dec;219(6):357-61.

18. Greenfield DS. Glaucoma associated with elevated episcleral venous pressure. J Glaucoma. 2000 Apr;9(2):190-94.

19. Weinreb RN, Karwatowski WSS.Glaucoma associated with elevated episcleral venous pressure. In: Ritch R, Shields BM, Krupin T (Eds). Glaucomas.2nd edn. St Louis: Mosby 1996:1143-55.

20. Rhee DJ, Gupta M, Moncavage MB, Moster ML, Moster MR. Idiopathic elevated episcleral venous pressure and open-angle glaucoma. Br J Ophthalmol 2009 Feb;93(2):231-34.

21. Radius RL,Maumanee AE. Dilated episcleral vessels and open angle glaucoma. Am J Ophthalmol 1978;86:31-35.

22. Groh MJ, Küchle M.Idiopathic episcleral venous stasis with secondary open-angle glaucoma (Radius-Maumenee syndrome) Klin Monatsbl Augenheilkd. 1997 Aug;211(2):131-32. 
23. Lämmer R.Secondary open angle glaucoma with idiopathic episcleral venous pressure (Radius-Maumenee syndrome). Sinus-otomy as operative procedure of choice. Ophthalmologe 2007 Jun;104(6): 515-16.

24. Buschmann W.Glaucoma in endocrine exophthalmus._Klin Monatsbl Augenheilkd 1986 Feb;188(2):138-40.

25. Alfano JE, Alfano PA. Glaucoma and the superior vena caval obstruction syndrome. Am J Ophthalmol 1956 Nov;42(5):68596.

26. Ishijima K, Kashiwagi K, Nakano K, Shibuya T, Tsumura T, Tsukahara S. Ocular manifestations and prognosis of secondary glaucoma in patients with carotid-cavernous fistula. Jpn J Ophthalmol 2003 Nov-Dec;47(6):603-08.

27. Gupta S, Thakur AS, Bhardwaj N, Singh H. Carotid cavernous sinus fistula presenting with pulsating exophthalmos and secondary glaucoma. J Indian Med Assoc 2008 May;106(5):312-46.

28. Keltner JL, Satterfield D, Dublin AB, Lee BC. Dural and carotid cavernous sinus fistulas. Diagnosis, management, and complications. Ophthalmology 1987 Dec;94(12):1585-600.

29. Wright JE. Orbital vascular anomalies. Trans Am Acad Ophthalmol Otolaryngol 1974 Jul-Aug;78(4):OP606-16.

30. Jørgensen JS, Guthoff R. Sturge-Weber syndrome: Glaucoma with elevated episcleral venous pressure. Klin Monatsbl Augenheilkd. 1987 Oct;191(4):275-78.

31. Phelps CD. The pathogenesis of glaucoma in Sturge-Weber syndrome. Ophthalmology 1978 Mar;85(3):276-86.

32. Awad AH, Mullaney PB, Al-Mesfer S, Zwaan JT.Glaucoma in SturgeWeber syndrome. J AAPOS 1999 Feb;3(1):40-45.

33. Olsen KE, Huang AS, Wright MM. The efficacy of goniotomy/ trabeculotomy in early-onset glaucoma associated with the SturgeWeber syndrome. J AAPOS 1998 Dec;2(6):365-68.

34. Board RJ, Shields MB. Combined trabeculotomy-trabeculectomy for the management of glaucoma associated wih Sturge-Weber syndrome. Ophthalmic Surg 1981 Nov;12(11):813-17.

35. Budenz DL, Sakamoto D, Eliezer R, Varma R, Heuer DK. Twostaged Baerveldt glaucoma implant for childhood glaucoma associated with Sturge-Weber syndrome. Ophthalmology 2000 Nov; 107(11):2105-10.

36. Amini H, Razeghinejad MR, Esfandiarpour B. Primary single-plate Molteno tube implantation for management of glaucoma in children with Sturge-Weber syndrome. Int Ophthalmol 2007 Dec;27(6): 345-50.
37. Hamush NG, Coleman AL, Wilson MR. Ahmed glaucoma valve implant for management of glaucoma in Sturge-Weber syndrome. Am J Ophthalmol 1999 Dec;128(6):758-60.

38. Audren F, Abitbol O, Dureau P,et al. Non-penetrating deep sclerectomy for glaucoma associated with Sturge-Weber syndrome. Acta Ophthalmol Scand 2006 Oct;84(5):656-60.

39. Bellows AR, Chylack LT Jr, Epstein DL, Hutchinson BT.Choroidal effusion during glaucoma surgery in patients with prominent episcleral vessels. Arch Ophthalmol 1979 Mar;97(3):493-97.

40. Shihab ZM, Kristan RW. Recurrent intraoperative choroidal effusion in Sturge-Weber syndrome. J Pediatr Ophthalmol Strabismus 1983 Nov-Dec;20(6):250-52.

41. Nelson GA, Edward DP, Wilensky JT. Ocular amyloidosis and secondary glaucoma. Ophthalmology 1999 Jul;106(7):1363-66.

42. Bansal RK, Gupta A, Agarwal A.Primary orbital amyloidosis with secondary glaucoma: case report. Orbit 1991;10:105.

43. Kranemann CF, Pavlin CJ, Trope GE. Ultrasound biomicroscopy in Sturge-Weber-associated glaucoma. Am J Ophthalmol 1998 Jan;125(1):119-21.

44. Prigent P, Courtheoux P, Le Coq P, Le Callonnec A, Urvoy M. Dural fistulae of the cavernous sinus and interventional neuroradiology. Apropos of 4 cases J Fr Ophtalmol 1996; 19(12):761-69.

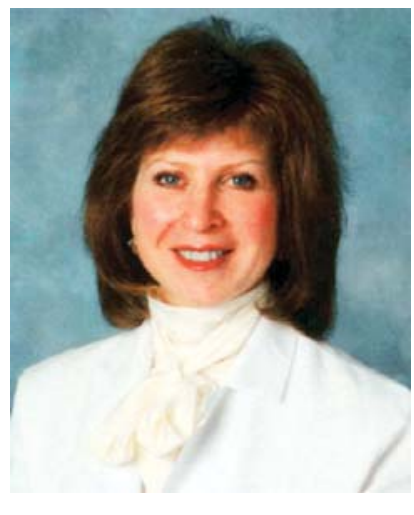

Marlene Moster

(marlenemoster@aol.com)

"The wonderful beauty of prayer is that the opening of our hearts is as natural as the opening of a flower. To let a flower open and bloom, it is only necessary to let it be, so if we simply are, if we become and remain still and silent, our heart cannot but be open, the spirit cannot but pour through into our whole being." 